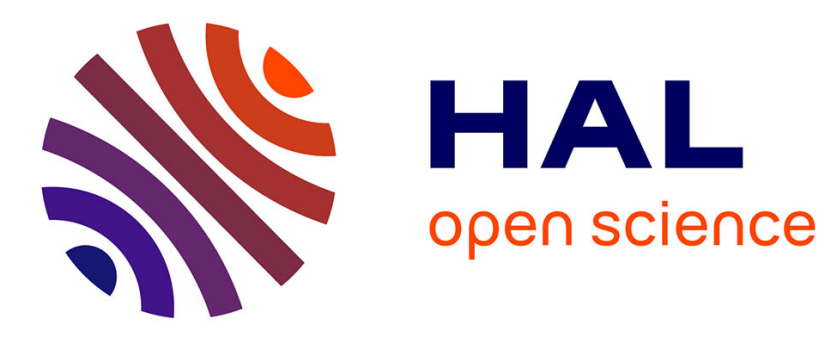

\title{
Shaping mycolactone for therapeutic use against inflammatory disorders
}

Laure Guenin-Mace, Ludivine Baron, Anne-Caroline Chany, Cédric Tresse, Sarah Saint-Auret, Friederike Jönsson, Fabien Le Chevalier, Pierre Bruhns, Georges Bismuth, Sophie Hidalgo-Lucas, et al.

\section{To cite this version:}

Laure Guenin-Mace, Ludivine Baron, Anne-Caroline Chany, Cédric Tresse, Sarah Saint-Auret, et al.. Shaping mycolactone for therapeutic use against inflammatory disorders. Science Translational Medicine, 2015, 7 (289), pp.289ra85 - 289ra85. 10.1126/scitranslmed.aab0458 . pasteur-01382767

\section{HAL Id: pasteur-01382767 \\ https://hal-pasteur.archives-ouvertes.fr/pasteur-01382767}

Submitted on 17 Oct 2016

HAL is a multi-disciplinary open access archive for the deposit and dissemination of scientific research documents, whether they are published or not. The documents may come from teaching and research institutions in France or abroad, or from public or private research centers.
L'archive ouverte pluridisciplinaire $\mathbf{H A L}$, est destinée au dépôt et à la diffusion de documents scientifiques de niveau recherche, publiés ou non, émanant des établissements d'enseignement et de recherche français ou étrangers, des laboratoires publics ou privés.

\section{(ㅇ)(1) $\$$}

Distributed under a Creative Commons Attribution - NonCommercial - ShareAlikel 4.0 


\section{Shaping mycolactone for therapeutic use against inflammatory disorders}

One-sentence summary: A synthetic surrogate of the mycobacterial macrolide mycolactone shows therapeutic potential against skin inflammation and inflammatory pain.

Laure Guenin-Macé ${ }^{1,2}$, Ludivine Baron ${ }^{1,2}$, Anne-Caroline Chany $^{3}$, Cédric Tresse ${ }^{3}$, Sarah SaintAuret $^{3}$, Friederike Jönsson ${ }^{4,5}$, Fabien Le Chevalier ${ }^{1}$, Pierre Bruhns ${ }^{4,5}$, Georges Bismuth ${ }^{6,7,8}$, Sophie Hidalgo-Lucas ${ }^{9}$, Jean-François Bisson ${ }^{9}$, Nicolas Blanchard $^{3}$, Caroline Demangel $^{1,2^{*}}$

${ }^{1}$ Institut Pasteur, Unité d'Immunobiologie de l'Infection, Paris, France

${ }^{2}$ CNRS URA 1961, Paris, France

3 Université de Strasbourg, Laboratoire de Chimie Moléculaire, ECPM-CNRS UMR7509,

France.

${ }^{4}$ Institut Pasteur, Unité Anticorps en Thérapie et Pathologie, Paris, France

${ }^{5}$ INSERM U760, Paris, France

${ }^{6}$ INSERM U1016, Institut Cochin, Paris, France

${ }^{7}$ Université Paris Descartes, Paris, France

${ }^{8}$ CNRS UMR 8104, Paris, France

${ }^{9}$ ETAP, Inflammation, Dermatologie et Toxicologie, Vandouvre-lès-Nancy, France

* Corresponding author. E-mail: demangel@pasteur.fr 


\section{Abstract}

Inflammation adversely affects the health of millions of people worldwide and there is an unmet medical need for better anti-inflammatory drugs. Here, we evaluated the therapeutic interest of mycolactone, a polyketide-derived macrolide produced by Mycobacterium ulcerans. Bacterial production of mycolactone in human skin causes a combination of ulcerative, analgesic and antiinflammatory effects. While ulcer formation is mediated by the pro-apoptotic activity of mycolactone on skin cells via hyper-activation of Wiskott-Aldrich Syndrome proteins, analgesia results from neuronal hyper-polarization via signaling through angiotensin II type 2 receptors. Mycolactone also blunts the capacity of immune cells to produce inflammatory mediators, by an independent mechanism of protein synthesis blockade. In an attempt to isolate the structural determinants of mycolactone's immunosuppressive activity, we screened a library of synthetic subunits of mycolactone for inhibition of cytokine production by activated $\mathrm{T}$ cells. The minimal structure retaining immunosuppressive activity was a truncated version of mycolactone, missing one of the two core-branched polyketide chains. This compound inhibited the inflammatory cytokine responses of human primary cells at non-cytotoxic doses, and bound to angiotensin II type 2 receptors comparably to mycolactone in vitro. Notably, it was considerably less toxic than mycolactone in human primary dermal fibroblasts modeling ulcerative activity. In mouse models of human diseases, it conferred systemic protection against chronic skin inflammation and inflammatory pain, with no apparent side effects. In addition to establishing the antiinflammatory potency of mycolactone in vivo, our study therefore highlights the translational potential of mycolactone core-derived structures as prospective immunosuppressants. 


\section{INTRODUCTION}

Whether mycolactone, the major virulence factor of Mycobacterium ulcerans, impacts the systemic generation of inflammatory mediators in infected hosts remains unclear (1-3). Mycolactone production by bacteria infecting the skin provokes focal lesions called Buruli ulcers (BU) that are marked by an association of tissue necrosis, local analgesia and defective inflammation (4). We reported previously that mycolactone-driven destruction of cutaneous tissues proceeds through hyper-activation of N-WASP, a protein controlling the junctional organization and coordinated migration of epidermal cells (5). Recently, mycolactone was shown to inhibit pain perception by binding to angiotensin II type 2 receptors $\left(\mathrm{AT}_{2} \mathrm{Rs}\right)$ on neurons, leading to potassium-dependent hyperpolarization (๑).

In addition to a lack of inflammatory infiltrates at the level of skin lesions (7), patients with BU display systemic alterations in their cellular immune responses, evidenced by an impaired capacity of $\mathrm{T}$ cells to produce cytokines ex-vivo upon stimulation with mitogenic agents (8-10). Contrary to wild-type strains, mycolactone-deficient mutants of $M$. ulcerans do not impair the capacity of $\mathrm{T}$ cells to produce interleukin (IL)-2 in animal models, showing that mycolactone is the cause of these cellular response defects (11). In vitro, nanomolar concentrations of mycolactone efficiently blocked the functional maturation of dendritic cells (12) and cytokine

production by activated lymphocytes, monocytes, macrophages and epithelial cell lines (13-17). Mycolactone also down-regulated the expression of L-selectin on naive $\mathrm{T}$ cells, profoundly impacting on lymphocyte homing and expansion upon antigenic stimulation in vivo (18). Although the molecular receptor mediating these effects remains to be identified, there is recent 
evidence showing that mycolactone operates by an original mechanism of post-transcriptional blockade of protein synthesis, selectively affecting membrane and secreted proteins (17).

Following release by bacterial infection of the skin, or upon subcutaneous injection, mycolactone diffuses into the peripheral blood and reaches lymphoid organs $(11,19)$. This diffusion capacity, combined with potent immunosuppressive and analgesic properties, make mycolactone a drug candidate for the treatment of inflammatory disorders. Its development for clinical use nevertheless faces two major challenges. Firstly, the chemical synthesis of this complex natural product is a costly, multi-step process $(1,20-22)$, which challenges bulk industrial production. Secondly, whether mycolactone can be engineered to dissociate immunosuppression and analgesia from cytotoxicity is currently unknown (23-25). Here we screened a large panel of structural variants of mycolactone in biochemical and cellular assays reflecting its biological activities. We identified a simplified and detoxified version of mycolactone that bound to analgesia-mediating receptors comparably to the natural product, and mimicked its inhibitory action on inflammatory cytokine production. Importantly, this synthetic compound efficiently protected mice against chronic skin inflammation and inflammatory pain, establishing the therapeutic potential of this mycolactone derivative.

\section{RESULTS}

Immune modulating and cytopathic features of mycolactone can be partially dissociated Mycolactone produced by M. ulcerans is composed of three structural modules, a 12-membered lactone ring and two polyketide-derived chains that are branched to the core in the north and south positions (Fig. 1). Bacteria produce a mixture of cis/trans isomers designated A/B. To 
investigate the contribution of each subunit of mycolactone $\mathrm{A} / \mathrm{B}$ to biological activity, we used synthetic compounds corresponding to the lactone core and fatty-acyl chains assembled in diverse combinations, and harboring variations in the structure and hydroxylation of the polyketide chains $(20,23)$ (Fig. 1). Variants were compared to mycolactone for their capacity to block the activation-induced production of IL-2 by Jurkat cells, using $\mathrm{IC}_{50}$ as a comparator (Fig. $2 \mathrm{~A}, \mathrm{~S} 1)$. In this $\mathrm{T}$ cell model, mycolactone dose-dependently inhibited the production of IL-2 upon cell stimulation with phorbol 12-myristate 13-acetate (PMA) and ionomycin (IO) with an $\mathrm{IC}_{50}$ of $40 \mathrm{nM}(13)$. Variants were also assessed for their cytopathic activity in the human epithelial cell line HeLa, a model that is highly susceptible to mycolactone-mediated anoïkis (5). Here, we compared variants for their capacity to induce cell detachment after $48 \mathrm{~h}$, conditions in which mycolactone induces $>80 \%$ cytotoxicity (Fig. $2 \mathrm{~A}, \mathrm{~S} 1$ ). Figure $2 \mathrm{~B}$ plots the aforementioned parameters of immunomodulation and cytotoxicity of each variant.

Notably, all variants were less active than mycolactone, indicating that each structural module of the natural molecule has a biological role (Fig. 2B, S1). Compared to mycolactone, immunomodulatory activity was best retained in compounds $\mathbf{3 2 b}, \mathbf{3 0}, \mathbf{5 r}$ and $\mathbf{5 b}\left(\mathrm{IC}_{50}\right.$ of $\left.1.5 \mu \mathrm{M}\right)$, in which the north chain is missing $(\mathbf{5 b}, \mathbf{5} \mathbf{r}$ and $\mathbf{3 0})$ or replaced by a 4-alkyl-1,2,3-triazole (32b). Amongst them, saturation of the lactone core (30) or substitution of the $\mathrm{C} 1^{\prime}-\mathrm{C} 7$ ' sector of the south chain with a cinnamyl (5r) did not alter activity. Of note, 32b, 30 and $\mathbf{5 r}$ were more cytotoxic than $\mathbf{5 b}$, showing that cytotoxicity and immunosuppressive activity can be, at least partially, dissociated. A second group of mycolactone analogues displaying $\mathrm{IC}_{50}$ in the 2.2-3.4 $\mu \mathrm{M}$ range encompassed derivatives with inverted and/or deoxy $\mathrm{C} 12^{\prime}, \mathrm{C} 13^{\prime}$ and $\mathrm{C} 15^{\prime}$ stereocenters. In accordance with previous reports (24), a significant loss in immunosuppressive and cytotoxic 
activity was observed when the hydroxyl group in position C12' was suppressed (5j). Likewise, modification of the $\mathrm{C} 1$ '-C5' sector of the southern fragment by introduction of a benzoyl motif was also detrimental to activity (5q). A last group of 9 analogues showed no detectable inhibitory activity in the IL-2 assay, in tested conditions ( $\left.\mathrm{IC}_{50} \geq 4 \mu \mathrm{M}\right)$. Their lack of reactivity indicated that shortening the polyketide chain and removing more than one out of three hydroxyl groups in the $\mathrm{C} 12$ '-C13'-C15' sector has dramatic impact on immunosuppressive activity. Intriguingly, variant $\mathbf{4 b}$ corresponding to $\mathrm{C} 8$-desmethyl mycolactone $\mathrm{A} / \mathrm{B}$ fell in this category, suggesting that intra-molecular interactions between the northern chain and lactone core may limit reactivity. Overall, this study showed that the structural requirements for cytotoxic and immunosuppressive activities do not strictly overlap. The $\mathbf{5 b}$ variant, corresponding to mycolactone without north chain and core C8-methyl, displayed an optimal ratio of immune suppression to cytotoxicity, prompting us to examine its biological properties in further detail.

\section{$5 b$ suppresses inflammatory responses in human primary cells}

To gain insight into the translational potential of $\mathbf{5 b}$, we next assessed its impact on the viability and functional biology of key subsets of human inflammatory cells. Polymorphonuclear neutrophils (PMN) dominate the early stages of inflammation, and activated PMN sustain inflammatory responses via the production of cytokines like TNF- $\alpha$ (26). PMN isolated from venous blood of healthy donors were incubated for up to $24 \mathrm{~h}$ with mycolactone or $\mathbf{5 b}$, prior to activation with PMA. Although the viability of PMN declined in culture, we did not observed increased mortality in the presence of mycolactone or $\mathbf{5 b}$, irrespective of the cell activation state (Fig. S2). Notably, exposure to mycolactone, and $\mathbf{5 b}$ to a lower extent, efficiently blocked the ability of PMN to release TNF- $\alpha$ upon activation (Fig. 3A). Production of TNF- $\alpha$ by LPS- 
stimulated monocyte-derived macrophages (MDM) was also potently inhibited by pre-incubation with mycolactone or $\mathbf{5 b}$, without evidence of cell mortality (Fig. 3B). Of note, prolonged exposure ( $>48 \mathrm{~h}$ ) of MDM to immunomodulatory concentrations of mycolactone or $\mathbf{5 b}$ eventually altered cell viability (Fig. 3C). In contrast, the viability of $\mathrm{CD}^{+} \mathrm{T}$ cells was not altered by exposure to mycolactone or $\mathbf{5 b}$ for up to $48 \mathrm{~h}$ (Fig. S3). Their PMA/IO-induced production of IL2 and interferon (IFN)- $\gamma$ was markedly inhibited by pre-incubation with mycolactone or $\mathbf{5 b}$ (as shown for IL-2 in Fig. 3D).

Mycolactone binding to $\mathrm{AT}_{2} \mathrm{R}$, evidenced by competition with an $\mathrm{AT}_{2} \mathrm{R}$ agonist in vitro, was previously reported to mediate analgesia (6). We found that mycolactone and $\mathbf{5 b}$ displaced the $\mathrm{AT}_{2} \mathrm{R}$ agonist with comparable efficacy (Fig. 3E). Finally, since BU formation involves primarily the destruction of human dermis by mycolactone, we used primary human dermal fibroblasts (HDF) to model the potential ulcerative properties of $\mathbf{5 b}$ in vivo. As shown in Figure 3F, HDF displayed a high susceptibility to mycolactone-mediated killing, with a $50 \%$ loss in cell viability upon incubation with nanomolar concentrations of mycolactone for $48 \mathrm{~h}$. In support for safe use in humans, the cytotoxicity of variant $\mathbf{5 b}$ was markedly lower.

Table 1 summarizes the $\mathrm{IC}_{50}$ measured for mycolactone and $\mathbf{5 b}$ in the biochemical and cellular assays described above. They show that $\mathbf{5 b}$ conserved the biological activities of mycolactone to different degrees. Capacity to bind $\mathrm{AT}_{2} \mathrm{R}$ expressed on recombinant cells was largely preserved in $\mathbf{5 b}$, suggesting that full and truncated molecules may have comparable analgesic effects in vivo. Variant $\mathbf{5 b}$ also mimicked mycolactone for inhibition of cytokine production by $\mathrm{PMN}, \mathrm{MDM}$ and $\mathrm{CD}^{+} \mathrm{T}$ cells, with a $162-320$ fold reduction in activity. 
Importantly, anti-inflammatory effects were always observed in the absence of cytotoxicity. In fact, the viability of PMN and $\mathrm{CD}^{+}{ }^{\mathrm{T}}$ cells was not altered by exposure to mycolactone or $\mathbf{5} \mathbf{b}$, in the conditions tested. In the mycolactone-susceptible MDM and HDF, 5b was 514 and 1910 times less toxic than mycolactone, respectively. In addition to be synthetically simpler than the mycobacterial factor, $\mathbf{5 b}$ may therefore have a broader therapeutic window.

\section{Mycolactone and $5 \mathrm{~b}$ both protect against chronic skin inflammation}

We used the PMA mouse model of chronic skin inflammation $(27,28)$ to evaluate the antiinflammatory potential of mycolactone and $\mathbf{5 b}$ in vivo. A $0.5 \mathrm{mg} / \mathrm{kg}$ dose was chosen for mycolactone, which is the maximum concentration allowing injections at $>2$ days intervals without induction of skin ulceration. Because it was less potent than mycolactone in cellular assays, we administered $\mathbf{5 b}$ at $5 \mathrm{mg} / \mathrm{kg}$, corresponding to the maximum solubility of the $10 \mathrm{x}$ injection solution in PBS. Repeated applications of PMA on the back of hairless mice (from $\mathrm{D}_{1}$ to $\mathrm{D}_{8}$ then at $\mathrm{D}_{10}$ and $\mathrm{D}_{12}$, Fig. $4 \mathrm{~A}$ ) triggered a visible inflammation of dorsal skin (Fig. 4B), characterized by cell infiltrates in dermis and epidermis, vascular dilation and tissue thickening (Fig. 4C-D). Notably, intraperitoneal injections of mycolactone at $\mathrm{D}_{0}, \mathrm{D}_{4}, \mathrm{D}_{8}$ and $\mathrm{D}_{12}$, and to a lower extent $\mathbf{5 b}$, significantly reduced both macroscopic and microscopic signs of inflammation (Fig. 4B-C, Table S1). Of note, the protection afforded by $\mathbf{5 b}$ was more similar to that of mycolactone in skin areas situated at the periphery of the site of PMA application (Fig. S4). In histopathologic scoring of skin inflammation, 5b more closely resembled mycolactone's antiinflammatory effects in the dermis (Fig. S4). In this tissue, a marked reduction in the recruitment of both acute and chronic inflammatory cells, fibrosis and vascular damage could be observed in both mycolactone- and $\mathbf{5 b}$-treated mice. 


\section{Systemic mycolactone and $5 \mathrm{~b}$ relieve local inflammatory pain}

Anti-nociceptive activity of mycolactone was recently demonstrated by injection of mycolactone in mouse footpads and local assessment of pain sensitivity to a thermal stimulus (6). Having shown that mycolactone and $\mathbf{5 b}$ exert anti-inflammatory effects at a distance from the injection site, we investigated whether systemic delivery of the molecules induced local control of pain. We used the formalin assay in mice, as it is considered a reliable model of nociception that allows to discriminate inflammatory and non-inflammatory pain (29). Injection of a formalin solution into mouse hindpaws induces two distinct periods of stereotypical licking and biting behaviors. The first 5 minutes reflect a direct effect on nociceptors (acute pain) while the second phase, lasting from 10 to $40 \mathrm{~min}$, involves primarily inflammatory processes (Fig. 5A). Figure 5B shows that intraperitoneal injection of mycolactone $(0.5 \mathrm{mg} / \mathrm{kg})$ or $\mathbf{5 b}(5 \mathrm{mg} / \mathrm{kg}) 1 \mathrm{~h}$ before formalin injection had no effect on the early phase of the assay. In contrast, both molecules were anti-nociceptive in the late phase (Fig. 5C), demonstrating their systemic and selective effect against inflammatory pain. As a centrally acting analgesic, morphine was anti-nociceptive in both phases.

\section{DISCUSSION}

Pathogenic species of mycobacteria have evolved to produce original polyketide synthase products, with virulence and immunomodulatory properties (30). This is well exemplified by $M$. ulcerans, which differs from its $M$. marinum ancestor essentially by the presence of giant plasmid-encoded polyketide synthases producing mycolactone $(31,32)$. Using cellular models, we and others have shown over the past few years that in addition to cause the formation of painless ulcers, mycolactone is a natural immunosuppressor operating via a novel mechanism of 
action $(12-15,17,18,33)$. Here, we demonstrate that mycolactone can be used therapeutically to suppress inflammatory responses. In agreement with cellular assays demonstrating its inhibitory activity on cytokine production by activated neutrophils, macrophages and $\mathrm{T}$ cells, systematically delivered mycolactone was effective at limiting inflammation in mouse models of skin inflammation and rheumatoid arthritis (Fig. S5).

Mycolactone was recently reported to reduce pain locally, by stimulating the angiotensin/Cox-1/PGE 2 pathway in neurons, and potentially other $\mathrm{AT}_{2} \mathrm{Rs}$ expressing cells such as macrophages or fibroblasts (34). In the present study, we showed that mycolactone is effective at controlling inflammatory pain generated distantly. Whether this analgesic effect operates via $\mathrm{AT}_{2} \mathrm{Rs}$, suppression of inflammatory cytokine production, or both mechanisms, will require more investigations. Our observation that mycolactone selectively reduces inflammatory pain in the formalin test in mice does not allow us to discriminate between one or the other of these mechanisms, as $\mathrm{PGE}_{2}$ and cytokine release both develop during the late phase. However, the high potency of mycolactone and $\mathbf{5 b}$ in suppressing inflammatory cytokine production, including proalgesic TNF- $\alpha$ (Fig. 3), strongly suggests that this immunomodulatory activity is at play. The identification of the yet mysterious molecular receptor by which mycolactone blocks cytokine production will be a profitable area of research, as it will allow to dissect further the mechanisms of its analgesic properties.

Since mycolactone is not easily amenable to large-scale synthesis, we aimed to determine whether its structure could be simplified without loss in biological activity. In vitro and in vivo assays identified the $\mathbf{5 b}$ subunit as an alternative to full mycolactone retaining capacity to block 
cytokine production by neutrophils, macrophages and lymphocytes, although with less potency. From a clinical perspective, $\mathbf{5 b}$ offers several advantages over the natural molecule, in addition to being easier to chemically synthesize. Firstly, its smaller size (572 vs $743 \mathrm{Da}$ ) should allow a better distribution of the product throughout the fluids and tissues of the body. Secondly, cellular assays showed that $\mathbf{5 b}$ retains the desirable (immunomodulatory and $\mathrm{AT}_{2} \mathrm{R}$ binding) properties of mycolactone relatively better than its undesirable (cytotoxic) ones. Accordingly, $\mathbf{5 b}$ delivered at 5 $\mathrm{mg} / \mathrm{kg}>3$ times at 2 days intervals was not ulcerative in mice. In comparison, injections of mycolactone at this frequency, and at ten times lower concentrations, caused skin lesions. The dosage regimen used in the present work to demonstrate the protective efficacy of $\mathbf{5 b}$ could therefore be intensified to improve clinical benefit, without inducing side effects. In conclusion, our study provides the proof-of-concept that mycolactone derivatives have a therapeutic potential. It paves the way for future research on mycolactone-inspired molecules, for the treatment of inflammatory pain and inflammatory diseases.

\section{MATERIALS AND METHODS}

\section{Study design}

This study was designed to evaluate the potential of mycolactone, and a series of truncated synthetic variants of this natural product, as clinical immunosuppressants. A first screen of the molecules was performed in human cell lines, leading to the identification of a lead candidate retaining the immunosuppressive properties of mycolactone relatively better than its cytopathic activity. The translational potential of mycolactone and synthetic surrogate was then evaluated in 
functionally relevant subsets of human primary cells (from at least three donors) and mouse models of inflammatory disorders (PMA-induced skin inflammation and formalin-induced pain). Mean clinical scores of inflammation were determined in mice randomly grouped on a weight basis, in a double blind manner. Outliers were defined as at least $1.5 \times$ IQR greater than the upper quartile, or $1.5 \times$ IQR less than the lower quartile (IQR being the interquartile range $=$ upper quartile value minus lower quartile value). There was no outlier in the skin inflammation study. Those detected in the formalin-induced pain assay were excluded from the statistical analysis.

\section{Natural mycolactone and synthetic variants}

Mycolactone was purified from Mycobacterium ulcerans bacterial pellets (strain 1615, ATCC $35840)$ then quantified by spectrophotometry $(3,35)$. Modular variants of mycolactone were synthesized as described $(20,23)$. Stock solutions of mycolactone and variants were prepared in dimethyl sulfoxide (DMSO), then diluted 1000x in culture medium for cellular assays or 10x in phosphate buffered saline (PBS) before injection in animals. In all cases, controls exposed to the same volume of vehicle were included.

\section{Cell cultures}

HeLa cells (ATCC CCL-2 ${ }^{\mathrm{TM}}$ ), Jurkat E6.1 (ATCC TIB-152 ${ }^{\mathrm{TM}}$ ) T cells and adult HDF (Life Technologies, C-013-5C) cells were cultured in RPMI Glutamax ${ }^{\text {TM }}$ (Life Technologies), supplemented with $10 \%$ heat-inactivated fetal calf serum (FCS) (Invitrogen) and penicillin/streptomycin $(100 \mathrm{U} / \mathrm{ml}, 100 \mu \mathrm{g} / \mathrm{ml})$. Human primary T cells were isolated from blood donors by Ficoll density gradient centrifugation and $\mathrm{CD}^{+} \mathrm{T}$ cell purification by negative depletion (Miltenyi Biotec). Human primary macrophages were obtained from peripheral blood- 
derived monocytes, isolated by adhesion to tissue culture plastic-ware and cultured with $10 \mathrm{ng} / \mathrm{ml}$ human GM-CSF (Peprotech) for 7-12 days. For PMN isolation, blood samples from normal human donors drawn in EDTA were fractionated by density centrifugation on Lympholyte-Poly separation medium (Cedarlane Labs) as described (36), and PMN maintained in X-Vivo 15 medium (BioWhittaker).

\section{Assays of cytotoxic and immunosuppressive activity}

Detachment-induced cell death studies used HeLa cells seeded in $96-$ well plates $\left(10^{4}\right.$ cells/well $)$ and incubated with variants or mycolactone $(16 \mu \mathrm{M})$, or vehicle as control, for $48 \mathrm{~h}$ prior to enumeration of cells excluding Trypan Blue. The differential impact of mycolactone and $\mathbf{5 b}$ on the viability of human primary $\mathrm{HDF}, \mathrm{MDM}$ and $\mathrm{CD}^{+} \mathrm{T}$ lymphocytes was measured with the methyl-thiazolyl-tetrazolium (MTT) reduction assay. We used phosphatidylserine exposure (Annexin V staining) and loss of membrane integrity (propidium iodide (PI) staining) to further assess the induction of apoptosis in human primary $\mathrm{CD}^{+} \mathrm{T}$ lymphocytes and PMN. Immunosuppressive activity on T cells was measured through the inhibition of IL-2 and IFN- $\gamma$

production by Jurkat or human primary $\mathrm{CD}^{+} \mathrm{T}$ lymphocytes incubated with mycolactone or $\mathbf{5 b}$ for $1 \mathrm{~h}$ prior to $16 \mathrm{~h}$ of activation with PMA/IO, as described (13). Human primary PMN were incubated with mycolactone or $\mathbf{5 b}$ for $1-24 \mathrm{~h}$ before $2 \mathrm{~h}$ of activation with $100 \mathrm{ng} / \mathrm{ml}$ PMA. Human primary MDM were incubated with mycolactone or $\mathbf{5 b}$ for $1 \mathrm{~h}$ prior to $16 \mathrm{~h}$ of activation with $1 \mu \mathrm{g} / \mathrm{ml}$ LPS. Supernatants of PMN and MDM were then collected to quantify TNF- $\alpha$ release using ELISA. Mean percentages of inhibition of viability or cytokine release were calculated in duplicates, relative to vehicle controls. 


\section{Competitive binding to $\mathrm{AT}_{2} \mathrm{R}$}

Differential binding of mycolactone and $\mathbf{5 b}$ to $\mathrm{AT}_{2} \mathrm{R}$ was assessed through dose-dependent displacement of the binding of an agonist radioligand ([ $\left.{ }^{125} \mathrm{I}\right] \mathrm{CGP} 42,112 \mathrm{~A}$ at $\left.0.01 \mathrm{nM}\right)$ from recombinant HEK cell membrane preparations (Cerep Inc, Seattle, WA, Assay reference 0026).

\section{Mice}

Studies on PMA-induced skin inflammation and formalin-induced pain used Hairless mice (Skh1) and OF1 mice (Crl:OF1) respectively, both purchased at Charles River and housed in conventional animal facilities of ETAP-Ethologie Appliquée. Before experimentation, animals were housed for 5 days in temperature-, humidity- and light-controlled conditions (inverted $12 \mathrm{~h}$ light-dark cycle, light off at 8 am). Mice between 7 and 9 weeks of age were used in compliance with the European Communities Council Directive of 22 September 2010 on the approximation of laws, regulations, and administrative provisions of the Member States regarding the protection of animals used for scientific purposes, the rules edicted by the ASAB Ethical Committee for the treatment of animals in behavioral research and teaching (Animal Behavior 2006;71:245-253), the NIH Guide for the Care and Use of Laboratory Animals and the UK legislation of in vivo aspects in inflammation research. The studies received the approval by the French Ministry of Higher Education and Research (agreements no. CELMEA-2012-0021 and 00404.01).

\section{PMA-induced skin inflammation}

Hairless Skh-1 mice were randomized in 4 groups of 6 mice after the acclimatization period. Inflammation was induced by a daily application of $20 \mu \mathrm{g}$ of PMA on dorsal skin, from $\mathrm{D}_{1}$ to $\mathrm{D}_{8}$ then at $\mathrm{D}_{10}$ and $\mathrm{D}_{12}$, as previously described (27). Mycolactone $(0.5 \mathrm{mg} / \mathrm{kg}), \mathbf{5 b}(5 \mathrm{mg} / \mathrm{kg})$, or vehicle as control, were injected intraperitoneally at $\mathrm{D}_{0}, \mathrm{D}_{4}, \mathrm{D}_{8}$ and $\mathrm{D}_{12}$. Administration of 
mycolactone or $\mathbf{5 b}$ with this regimen did not induce tissue damage at the site of injection. Inflammation of mouse dorsal skin was scored daily by clinical examination of the animals, and measure of an index of cutaneous inflammation ( 0 [no or no further skin inflammation], 1 [weak skin inflammation], 2 [moderate skin inflammation], 3 [important skin inflammation], and 4 [very important skin inflammation]) in three areas: the site of PMA application, the periphery of this site and the rest of the mouse dorsum. A global score of the external aspect of cutaneous inflammation was then calculated, corresponding to the sum of these 3 measures (Table S1). Mice were sacrificed at $\mathrm{D}_{14}$, and photos of the mouse dorsum were taken. Biopsies were harvested at the different sites, fixed and stored in Roti $^{\circledR}$-Histofix $4 \%$ solution (Carl Roth, Karlsruhe, Germany) for histological examination at different depth of 6-10 cross-sections ( $5 \mu \mathrm{m}$ thickness) and stained with hematoxylin and eosin. Inflammation was scored in epidermis, dermis and hypodermis on the basis of tissue-specific histopathological parameters. A global histopathological score was then calculated (0-44), corresponding to the sum of these measures (Table S1).

\section{Formalin-induced pain}

The analgesic properties of mycolactone and $\mathbf{5 b}$ were tested in the formalin-induced paw licking test $(37,38)$ in OF1 mice. Briefly, mice were randomized in 5 groups of 8 mice after the acclimatization period. Mycolactone and $\mathbf{5 b}$ were administered intraperitoneally at 0.5 and 5 $\mathrm{mg} / \mathrm{kg}$ respectively, 60 minutes before the subcutaneous injection of the right hind-paw with 10 $\mu 1$ of a 5\% formalin solution. Two negative control groups, injected with PBS (neutral) or ethanol vehicle (vehicle) were tested in the same conditions. A group injected with $3 \mathrm{mg} / \mathrm{kg}$ morphine 15 minutes before formalin injection was used as a positive reference. The duration of formalin- 
injected paw licking and the number of body tremors during the early phase (0-5 min) and the late phase (10-40 $\mathrm{min})$ were recorded.

\section{Statistical analysis}

Data of the animal studies were analyzed with the Kruskal-Wallis test followed in case of significance $(\mathrm{p}<0.05)$ by the Mann-Whitney $U$ test (two-sided) to compare each treated group with its vehicle control. Statistical treatments were performed with the Statview ${ }^{\circledR} 5$ software (SAS Institute Inc., USA) and values of $\mathrm{P} \leq 0.05$ were considered significant. The Prism software (5.0d; La Jolla, CA) was used for graphical representation.

\section{SUPPLEMENTARY MATERIALS}

Fig. S1. Compared cytopathic and immunosuppressive effects of mycolactone and variants

Fig. S2. Viability of human primary PMN exposed to mycolactone or $\mathbf{5 b}$

Fig. S3. Viability of human primary $\mathrm{CD} 4^{+} \mathrm{T}$ lymphocytes exposed to mycolactone or $\mathbf{5 b}$

Fig. S4. Protective effect of mycolactone and $\mathbf{5 b}$ against PMA-induced skin inflammation

Fig. S5. Protective effect of mycolactone against rheumatoid arthritis

Table S1. Macroscopic and microscopic scoring of PMA-induced skin inflammation 


\section{REFERENCES AND NOTES}

1. A. C. Chany, C. Tresse, V. Casarotto, N. Blanchard, History, biology and chemistry of Mycobacterium ulcerans infections (Buruli ulcer disease). Nat Prod Rep 30, 1527-1567 (2013).

2. C. Demangel, T. P. Stinear, S. T. Cole, Buruli ulcer: reductive evolution enhances pathogenicity of Mycobacterium ulcerans. Nat Rev Microbiol 7, 50-60 (2009).

3. K. M. George, D. Chatterjee, G. Gunawardana, D. Welty, J. Hayman, R. Lee, P. L. Small, Mycolactone: a polyketide toxin from Mycobacterium ulcerans required for virulence. Science 283, 854-857 (1999).

4. L. Guenin-Mace, R. Oldenburg, F. Chretien, C. Demangel, Pathogenesis of skin ulcers: lessons from the Mycobacterium ulcerans and Leishmania spp. pathogens. Cell Mol Life Sci 71, 2443-50 (2014).

5. L. Guenin-Mace, R. Veyron-Churlet, M. I. Thoulouze, G. Romet-Lemonne, H. Hong, P. F. Leadlay, A. Danckaert, M. T. Ruf, S. Mostowy, C. Zurzolo, P. Bousso, F. Chretien, M. F. Carlier, C. Demangel, Mycolactone activation of Wiskott-Aldrich syndrome proteins underpins Buruli ulcer formation. J Clin Invest 123, 1501-12 (2013).

6. E. Marion, O. R. Song, T. Christophe, J. Babonneau, D. Fenistein, J. Eyer, F. Letournel, D. Henrion, N. Clere, V. Paille, N. C. Guerineau, J. P. Saint Andre, P. Gersbach, K. H. Altmann, T. P. Stinear, Y. Comoglio, G. Sandoz, L. Preisser, Y. Delneste, E. Yeramian, L. Marsollier, P. Brodin, Mycobacterial toxin induces analgesia in buruli ulcer by targeting the Angiotensin pathways. Cell 157, 1565-1576 (2014).

7. J. Guarner, J. Bartlett, E. A. Whitney, P. L. Raghunathan, Y. Stienstra, K. Asamoa, S. Etuaful, E. Klutse, E. Quarshie, T. S. van der Werf, W. T. van der Graaf, C. H. King, D. A. 
Ashford, Histopathologic features of Mycobacterium ulcerans infection. Emerg Infect Dis $\mathbf{9}$, 651-656 (2003).

8. D. Yeboah-Manu, E. Peduzzi, E. Mensah-Quainoo, A. Asante-Poku, D. Ofori-Adjei, G. Pluschke, C. A. Daubenberger, Systemic suppression of interferon-gamma responses in Buruli ulcer patients resolves after surgical excision of the lesions caused by the extracellular pathogen Mycobacterium ulcerans. J Leukoc Biol 79, 1150-1156 (2006).

9. R. Phillips, F. S. Sarfo, L. Guenin-Mace, J. Decalf, M. Wansbrough-Jones, M. L. Albert, C. Demangel, Immunosuppressive Signature of Cutaneous Mycobacterium ulcerans Infection in the Peripheral Blood of Patients with Buruli Ulcer Disease. J Infect Dis 200, 1675-84 (2009).

10. R. O. Phillips, F. S. Sarfo, J. Landier, R. Oldenburg, M. Frimpong, M. Wansbrough-Jones, K. Abass, W. Thompson, M. Forson, A. Fontanet, F. Niang, C. Demangel, Combined inflammatory and metabolic defects reflected by reduced serum protein levels in patients with Buruli ulcer disease. PLoS Negl Trop Dis 8, e2786 (2014).

11. H. Hong, E. Coutanceau, M. Leclerc, L. Caleechurn, P. F. Leadlay, C. Demangel, Mycolactone Diffuses from Mycobacterium ulcerans-Infected Tissues and Targets Mononuclear Cells in Peripheral Blood and Lymphoid Organs. PLoS Negl Trop Dis 2, e325 (2008).

12. E. Coutanceau, J. Decalf, A. Martino, A. Babon, N. Winter, S. T. Cole, M. L. Albert, C. Demangel, Selective suppression of dendritic cell functions by Mycobacterium ulcerans toxin mycolactone. $J$ Exp Med 204, 1395-1403 (2007).

13. S. Boulkroun, L. Guenin-Mace, M. I. Thoulouze, M. Monot, A. Merckx, G. Langsley, G. Bismuth, V. Di Bartolo, C. Demangel, Mycolactone suppresses T cell responsiveness by altering both early signaling and posttranslational events. J Immunol 184, 1436-1444 (2010). 
14. E. Coutanceau, L. Marsollier, R. Brosch, E. Perret, P. Goossens, M. Tanguy, S. T. Cole, P. L. Small, C. Demangel, Modulation of the host immune response by a transient intracellular stage of Mycobacterium ulcerans: the contribution of endogenous mycolactone toxin. Cell Microbiol 7, 1187-1196(2005).

15. A. A. Pahlevan, D. J. Wright, C. Andrews, K. M. George, P. L. Small, B. M. Foxwell, The inhibitory action of Mycobacterium ulcerans soluble factor on monocyte/T cell cytokine production and NF-kappa B function. J Immunol 163, 3928-3935 (1999).

16. R. E. Simmonds, F. V. Lali, T. Smallie, P. L. Small, B. M. Foxwell, Mycolactone inhibits monocyte cytokine production by a posttranscriptional mechanism. J Immunol 182, 2194$2202(2009)$.

17. B. S. Hall, K. Hill, M. McKenna, J. Ogbechi, S. High, A. E. Willis, R. E. Simmonds, The Pathogenic Mechanism of the Mycobacterium ulcerans Virulence Factor, Mycolactone, Depends on Blockade of Protein Translocation into the ER. PLoS Pathog 10, e1004061 (2014).

18. L. Guenin-Mace, F. Carrette, F. Asperti-Boursin, A. Le Bon, L. Caleechurn, V. Di Bartolo, A. Fontanet, G. Bismuth, C. Demangel, Mycolactone impairs T cell homing by suppressing microRNA control of L-selectin expression. Proc Natl Acad Sci U S A 108, 12833-12838 (2011).

19. F. S. Sarfo, F. Le Chevalier, N. Aka, R. O. Phillips, Y. Amoako, I. G. Boneca, P. Lenormand, M. Dosso, M. Wansbrough-Jones, R. Veyron-Churlet, L. Guenin-Mace, C. Demangel, Mycolactone diffuses into the peripheral blood of buruli ulcer patients implications for diagnosis and disease monitoring. PLoS Negl Trop Dis 5, e1237 (2011). 
20. A. C. Chany, V. Casarotto, M. Schmitt, C. Tarnus, L. Guenin-Mace, C. Demangel, O. Mirguet, J. Eustache, N. Blanchard, A diverted total synthesis of mycolactone analogues: an insight into buruli ulcer toxins. Chemistry 17, 14413-14419 (2011).

21. P. Gersbach, A. Jantsch, F. Feyen, N. Scherr, J. P. Dangy, G. Pluschke, K. H. Altmann, A Ring-Closing Metathesis (RCM)-Based Approach to Mycolactones A/B. Chem-Eur J 17, 13017-13031 (2011).

22. Y. Kishi, Organic Synthesis Toward Small-Molecule Probes and Drugs Special Feature: Chemistry of mycolactones, the causative toxins of Buruli ulcer. Proc Natl Acad Sci U S A 108, 6699-702 (2011).

23. A. C. Chany, R. Veyron-Churlet, C. Tresse, V. Mayau, V. Casarotto, F. Le Chevalier, L. Guenin-Mace, C. Demangel, N. Blanchard, Synthetic Variants of Mycolactone Bind and Activate Wiskott-Aldrich Syndrome Proteins. J Med Chem 57, 7382-95 (2014).

24. H. Hong, T. Stinear, J. Porter, C. Demangel, P. F. Leadlay, A Novel Mycolactone Toxin Obtained by Biosynthetic Engineering. Chembiochem 8, 2043-2047 (2007).

25. N. Scherr, P. Gersbach, J. P. Dangy, C. Bomio, J. Li, K. H. Altmann, G. Pluschke, Structureactivity relationship studies on the macrolide exotoxin mycolactone of Mycobacterium ulcerans. PLoS Negl Trop Dis 7, e2143 (2013).

26. W. M. Nauseef, N. Borregaard, Neutrophils at work. Nat Immunol 15, 602-611 (2014).

27. J. F. Bisson, S. Hidalgo-Lucas, M. Bouschbacher, L. Thomassin, Effects of TLC-Ag dressings on skin inflammation. J Dermatol 40, 463-470 (2013).

28. P. A. d'Alessio, M. Mirshahi, J. F. Bisson, M. C. Bene, Skin repair properties of d-Limonene and perillyl alcohol in murine models. Antiinflamm Antiallergy Agents Med Chem 13, 29-35 (2014). 
29. S. Hunskaar, K. Hole, The Formalin Test in Mice - Dissociation between Inflammatory and Noninflammatory Pain. Pain 30, 103-114 (1987).

30. L. Guenin-Mace, R. Simeone, C. Demangel, Lipids of Pathogenic Mycobacteria: Contributions to Virulence and Host Immune Suppression. Transbound Emerg Dis 56, 25568 (2009).

31. T. P. Stinear, A. Mve-Obiang, P. L. Small, W. Frigui, M. J. Pryor, R. Brosch, G. A. Jenkin, P. D. Johnson, J. K. Davies, R. E. Lee, S. Adusumilli, T. Garnier, S. F. Haydock, P. F. Leadlay, S. T. Cole, Giant plasmid-encoded polyketide synthases produce the macrolide toxin of Mycobacterium ulcerans. Proc Natl Acad Sci US A 101, 1345-1349 (2004).

32. T. P. Stinear, T. Seemann, S. Pidot, W. Frigui, G. Reysset, T. Garnier, G. Meurice, D. Simon, C. Bouchier, L. Ma, M. Tichit, J. L. Porter, J. Ryan, P. D. Johnson, J. K. Davies, G. A. Jenkin, P. L. Small, L. M. Jones, F. Tekaia, F. Laval, M. Daffe, J. Parkhill, S. T. Cole, Reductive evolution and niche adaptation inferred from the genome of Mycobacterium ulcerans, the causative agent of Buruli ulcer. Genome Res 17, 192-200 (2007).

33. B. Hall, R. Simmonds, Pleiotropic molecular effects of the Mycobacterium ulcerans virulence factor mycolactone underlying the cell death and immunosuppression seen in Buruli ulcer. Biochemical Society transactions 42, 177-183 (2014).

34. A. H. Danser, P. Anand, The Angiotensin II Type 2 Receptor for Pain Control. Cell 157, 1504-1506 (2014).

35. T. Spangenberg, Y. Kishi, Highly sensitive, operationally simple, cost/time effective detection of the mycolactones from the human pathogen Mycobacterium ulcerans. Chem Commun 46, 1410-1412 (2010).

36. H. Oh, B. Siano, S. Diamond, Neutrophil isolation protocol. J Vis Exp 17 (2008). 
37. D. Dubuisson, S. G. Dennis, The formalin test: a quantitative study of the analgesic effects of morphine, meperidine, and brain stem stimulation in rats and cats. Pain 4, 161-174 (1977).

38. A. Wisner, E. Dufour, M. Messaoudi, A. Nejdi, A. Marcel, M. N. Ungeheuer, C. Rougeot, Human Opiorphin, a natural antinociceptive modulator of opioid-dependent pathways. Proc Natl Acad Sci U S A 103, 17979-17984 (2006).

Acknowledgments: We thank D. Mathis and C. Benoist (Harvard Medical School, Boston, MA) for the KRN B6 mice and B. David-Watine (Institut Pasteur, Paris, France) for help with human fibroblast cultures.

Funding: This work was supported by the Fondation de la Recherche Médicale (FRM 2012 DEQ20120323704), the Association Raoul Follereau and the Région Ile de France (dim130027).

Author contributions: L.G.M., L.B., F.J., F.L.C., G.B., S.H.L. and J.F.B. performed the experiments. A.-C.C, C.T., S.S.-A. and N.B. synthesized the mycolactone variants. P.B. provided mice and consultation regarding the $\mathrm{K} / \mathrm{BxN}$ serum arthritis experiments. L.G.M., F.J., G.B., J.F.B. and C.D. designed all experiments. J.F.B. and C.D. performed the statistical analyses. Data interpretation and writing of the manuscript were performed by N.B. and C.D.

Competing interests: L.G.M., A.-C.C., G.B., N.B. and C.D. hold a patent on structural variants of mycolactone for use in modulating inflammation, immunity and pain. 
Fig. 1.
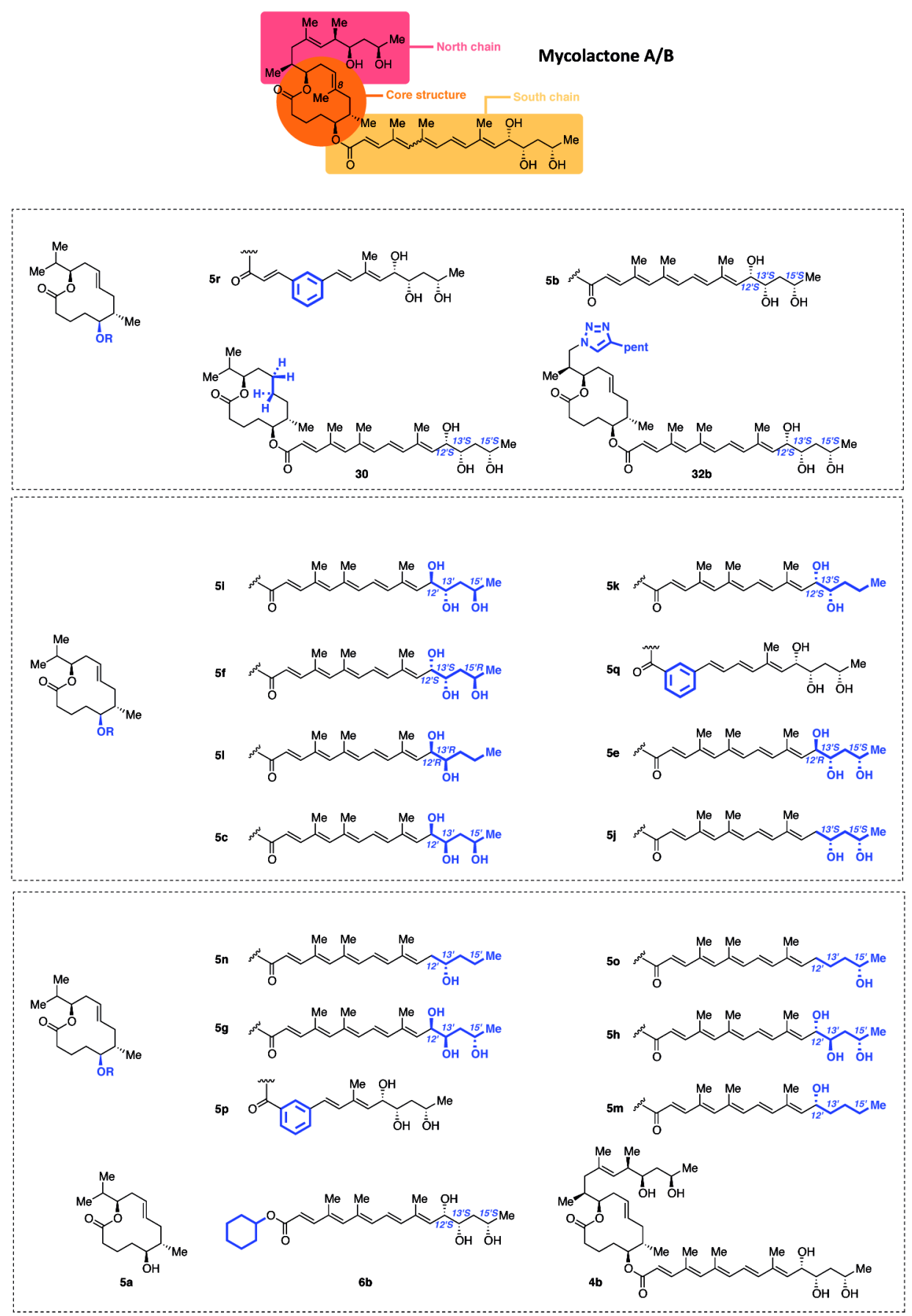

Fig. 1. Structure of mycolactone A/B from $M$. ulcerans and synthetic variants used in this study. Dotted line blocks correspond to the three groups of variants shown in Fig. 2B. 
Fig. 2.

\begin{tabular}{|c|c|c|c|c|}
\hline A & $\begin{array}{l}\text { Myco } \\
\text { Variant }\end{array}$ & $\begin{array}{l}\text { PMA/I } \\
\text { stimulat }\end{array}$ & & \multirow{3}{*}{ IL-2 production assay } \\
\hline \multirow{2}{*}{ Jurkat $T$ cells } & $\downarrow$ & 1h $\downarrow$ & $16 \mathrm{~h}$ & \\
\hline & & $\begin{array}{l}\text { Myco } \\
\text { Variant }\end{array}$ & & \\
\hline HeLa cells & $24 \mathrm{~h}$ adhesion & $\downarrow$ & $48 \mathrm{~h}$ & Viability assay \\
\hline
\end{tabular}

B

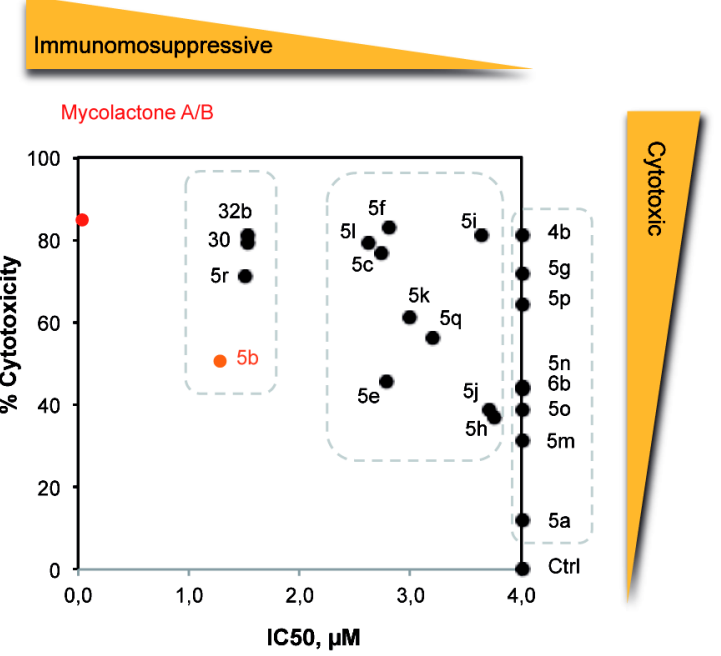

Fig. 2. Immune modulating and cytopathic features of mycolactone can be partially dissociated. (A) Study protocol. (B) The mean cytotoxicity of mycolactone and variants in epithelial cells, and mean capacity to inhibit IL-2 production by activated lymphocytes, are shown. 
Fig. 3.

A

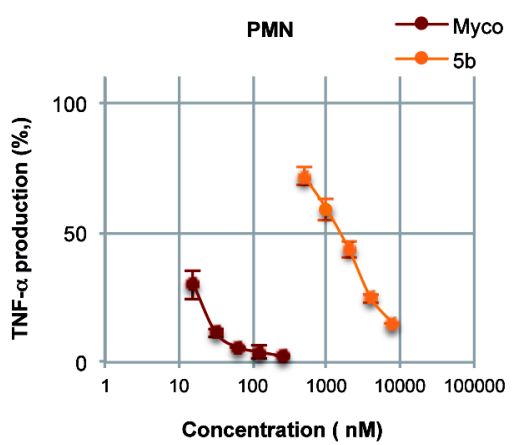

C

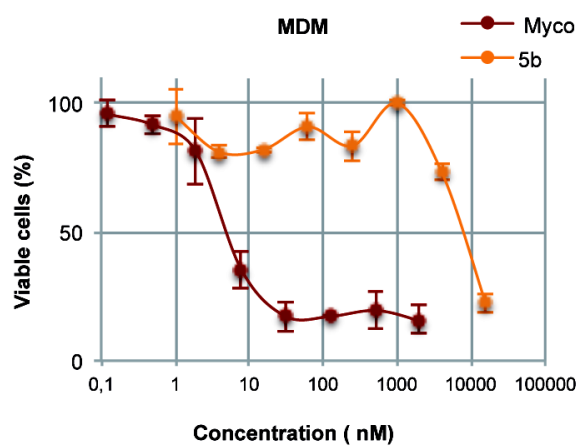

B

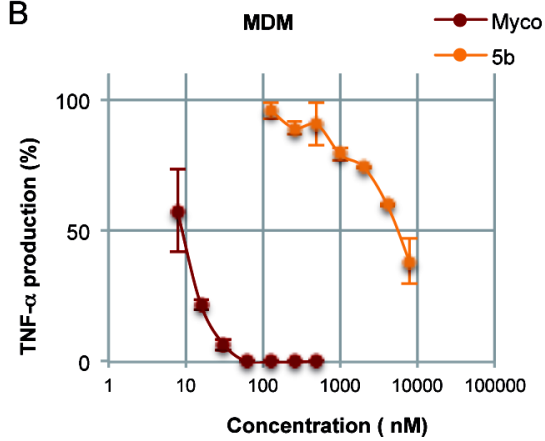

D

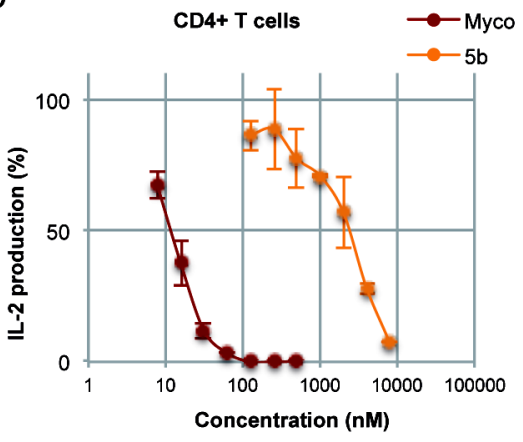

$\mathrm{E}$
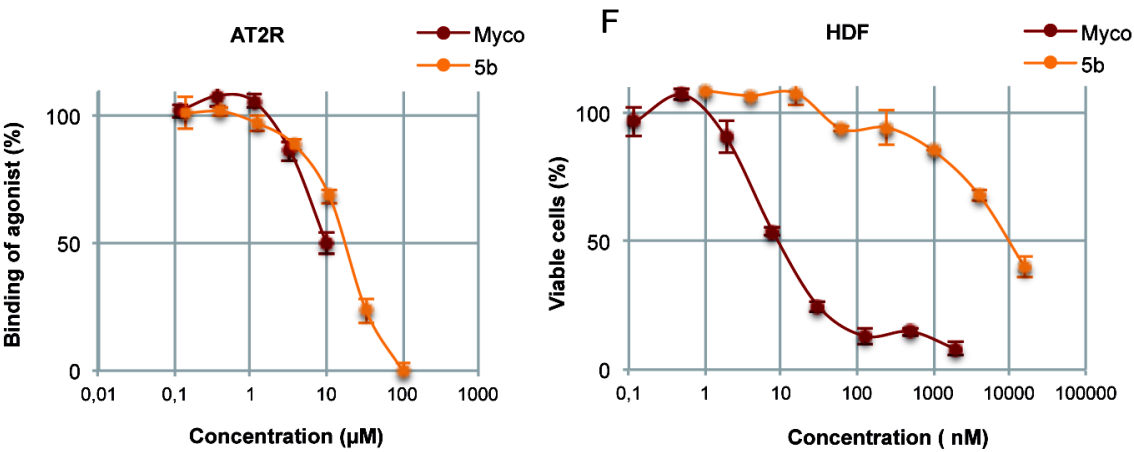

Fig. 3. Immunomodulatory and analgesic potential of 5b. (A) Production of of TNF- $\alpha$ by PMN incubated with mycolactone, $5 \mathrm{~b}$ or solvent as control, for $14 \mathrm{~h}$ then stimulated with PMA for $2 \mathrm{~h}$. (B) Production of TNF- $\alpha$ by MDM incubated with mycolactone, 5 b or solvent, for $1 \mathrm{~h}$ then stimulated with LPS for $16 \mathrm{~h}$. (C) Cell viability, as assessed by MTT reduction, of MDM incubated with mycolactone, $\mathbf{5 b}$ or solvent for $72 \mathrm{~h}$. (D) Production of IL-2 by human CD4+ T cells incubated with mycolactone, $\mathbf{5 b}$ or solvent, for $\mathbf{1 h}$ then stimulated with PMA/IO for $16 \mathrm{~h}$. Data shown in (A-D) are mean inhibition +/- SD of duplicates, relative to solvent, and are representative of $>2$ donors. (E) Competitive binding of mycolactone and $5 \mathbf{b}$ to human $\mathrm{AT}_{2}$ Rs. Data are Mean +/- SD of duplicates. (F) Cell viability, as assessed by MTT reduction, of HDF incubated with mycolactone, $\mathbf{5 b}$ or solvent for $\mathbf{7 2 h}$. Data are mean percentages +/- SD of duplicates, relative to solvent, and are representative of 3 experiments. 
Fig. 4

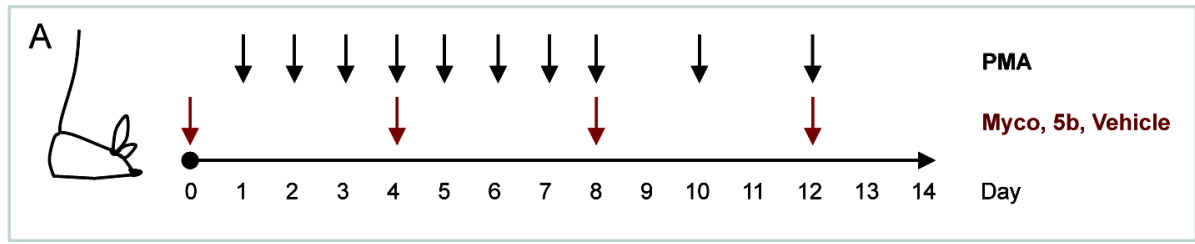

B Ctrl

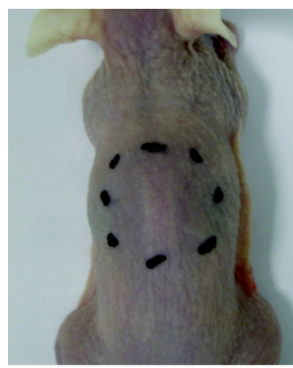

PMA / Vehicle

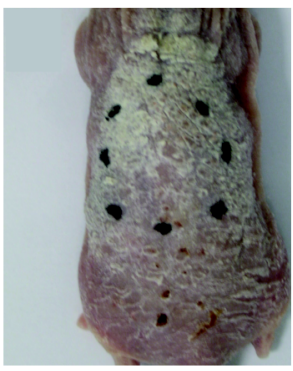

PMA / Myco

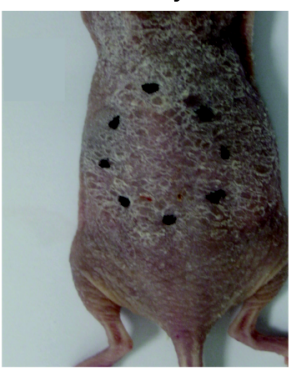

PMA / 5b

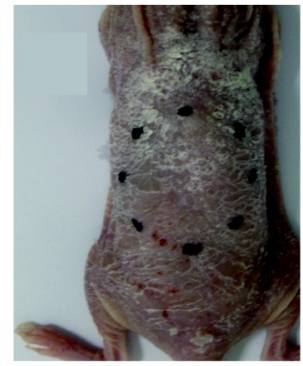

C

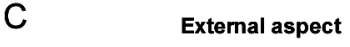

䢰

10
8
6
$4-$
2
0

External aspect

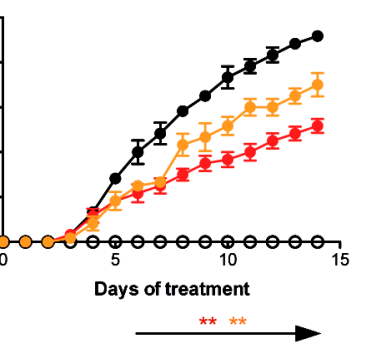

PMA / Vehicle
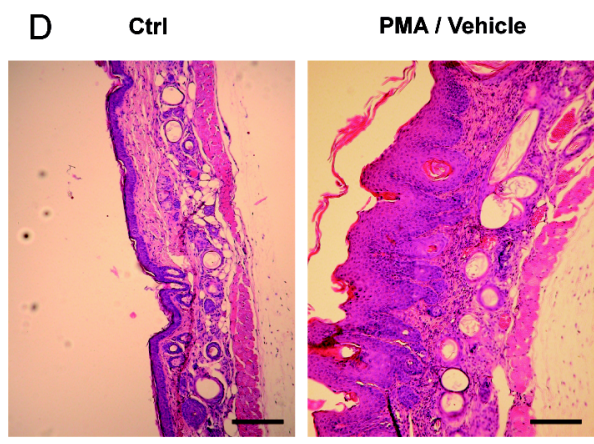

$\theta$ Ctri

$\multimap$ PMA/Vehicle

- PMA/Myco

- PMA/5b

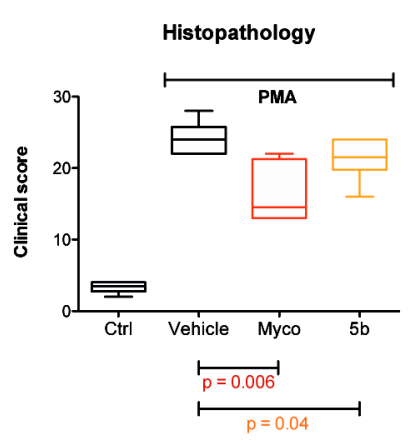

PMA / Myco

PMA / 5b
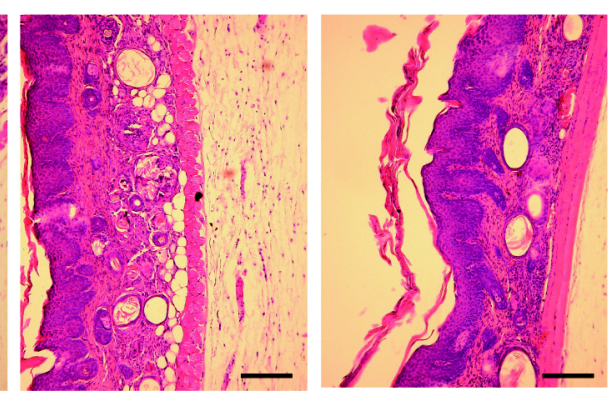

Fig. 4. Mycolactone and 5b protect against PMA-induced skin inflammation. (A) Study protocol (B) External aspect of PMA-treated mice following treatment with mycolactone (Myco), 5b, or vehicle (Vehicle). Animals not receiving PMA were included as controls (Ctrl). (C) Inflammation scores, as determined by visual (left) or histopathological (right) analysis of mouse dorsal skin. Data are presented as Mean +/- SD (left) or Box and Whiskers (right). (D) Hematoxylin/eosin staining of skin sections. Scale bars: $100 \mu \mathrm{m}$. Pictures in (B) and (C) are from a representative mouse in each group. (Mann-Whitney $U$ test on means; $n=6 ;{ }^{*} P<0.01$ vs. PMA/Vehicle). 
Fig. 5.
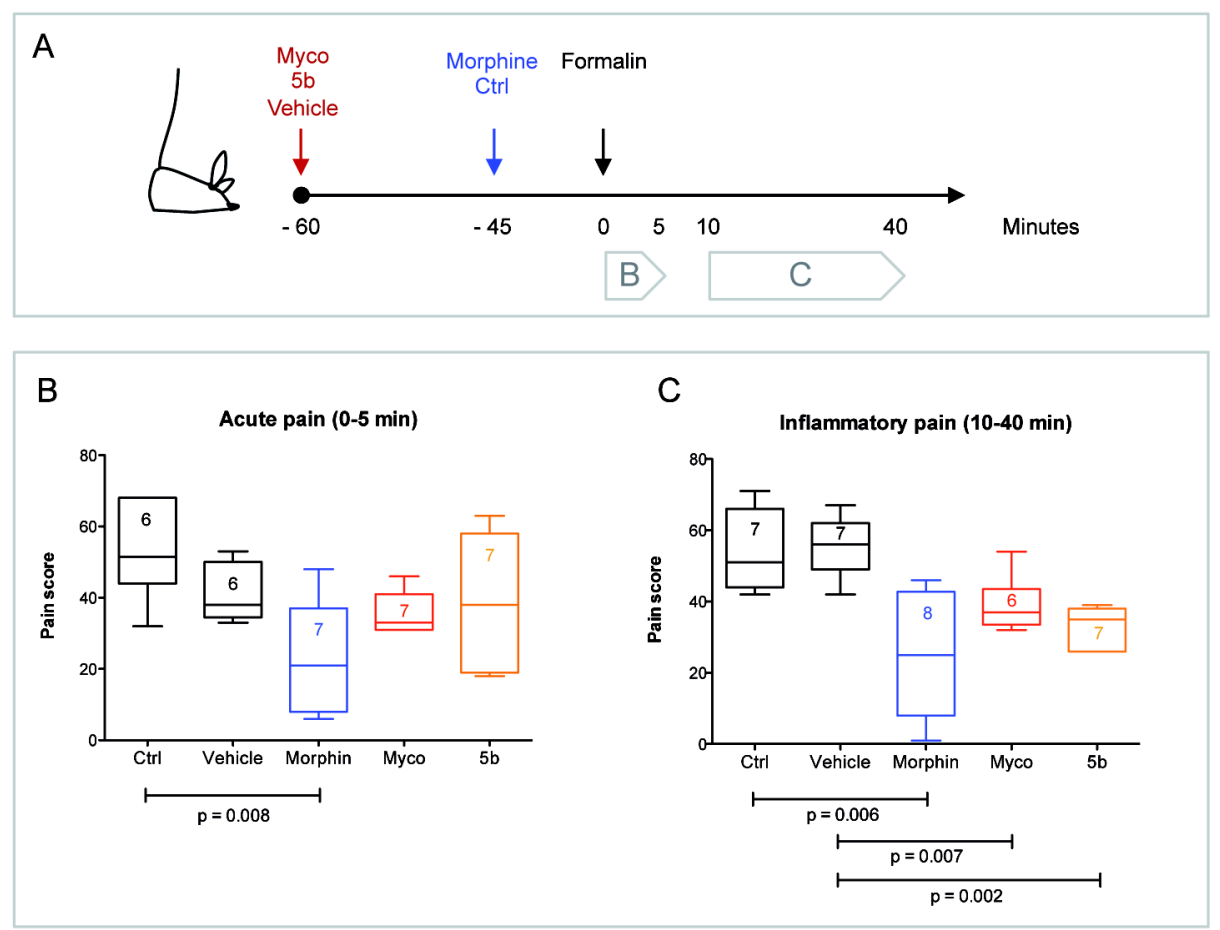

Fig. 5. Systemic mycolactone and 5b relieve local inflammatory pain. (A) Study protocol. Pain scores measured during the early (B) and late (C) phases of the formalin test are shown, as indicators of acute and inflammatory pain, respectively. Data are rank sum of paw licking duration and body tremor number in each group, presented as Box and Whiskers (Mann-Whitney $U$ test on trimmed means; $n$ values indicated in each box). 
Table 1. Compared cytopathic and immunosuppressive activities of mycolactone and $\mathbf{5 b}$ in human primary cells, and binding to analgesia-mediating receptors in vitro.

\begin{tabular}{|c|c|c|c|c|c|c|c|}
\hline Cells & PMN & \multicolumn{2}{|c|}{ MDM } & \multicolumn{2}{c|}{ T CD4 } & HDF & tHEK $^{+}$ \\
\hline Assay & $\begin{array}{c}\text { PMA- } \\
\text { induced } \\
\text { production } \\
\text { of TNF- } \alpha\end{array}$ & $\begin{array}{c}\text { LPS- } \\
\text { induced } \\
\text { production } \\
\text { of TNF- } \alpha\end{array}$ & $\begin{array}{c}\text { Cell } \\
\text { viability }\end{array}$ & $\begin{array}{c}\text { PMA/IO- } \\
\text { induced } \\
\text { production } \\
\text { of IL-2 }\end{array}$ & $\begin{array}{c}\text { PMA/IO- } \\
\text { induced } \\
\text { production } \\
\text { of IFN- } \gamma\end{array}$ & $\begin{array}{c}\text { Cell } \\
\text { viability }\end{array}$ & $\begin{array}{c}\mathrm{AT}_{2} \mathrm{R} \\
\text { binding }\end{array}$ \\
\hline $\mathbf{5 b}^{\mathbf{b}}$ & $\begin{array}{c}2.0+/-0.7 \\
(\mu \mathrm{M})\end{array}$ & $\begin{array}{c}3.5+/-2.6 \\
(\mu \mathrm{M})\end{array}$ & $\begin{array}{c}9.0+/-1.4 \\
(\mu \mathrm{M})\end{array}$ & $\begin{array}{c}3.9+/-3.4 \\
(\mu \mathrm{M})\end{array}$ & $\begin{array}{c}1.8+/-1.3 \\
(\mu \mathrm{M})\end{array}$ & $\begin{array}{c}12.0+/-4.2 \\
(\mu \mathrm{M})\end{array}$ & $\begin{array}{c}16.0 \\
(\mu \mathrm{M})\end{array}$ \\
\hline $\mathbf{M y c o}^{\mathbf{b}}$ & $13+/-4$ & $12+/-6$ & $18+/-18$ & $12+/-5$ & $7+/-3$ & $6+/-3$ & 9.2 \\
$(\mathrm{nM})$ & $(\mathrm{nM})$ & $(\mathrm{nM})$ & $(\mathrm{nM})$ & $(\mathrm{nM})$ & $(\mathrm{nM})$ & $(\mu \mathrm{M})$ \\
\hline $\begin{array}{c}\text { IC }_{\mathbf{5 0}} \\
\text { ratio }^{\mathbf{c}}\end{array}$ & 162 & 285 & 514 & 320 & 268 & 1910 & 2 \\
\hline
\end{tabular}

${ }^{\mathrm{a}} \mathrm{AT}_{2} \mathrm{R}$-transfected HEK cells

${ }^{\mathrm{b}}$ Data in cellular assays are mean $\mathrm{IC}_{50}+/-\mathrm{SD}$ from at least 2 donors.

${ }^{\mathrm{c}} \mathbf{5 b}$ versus Myco 

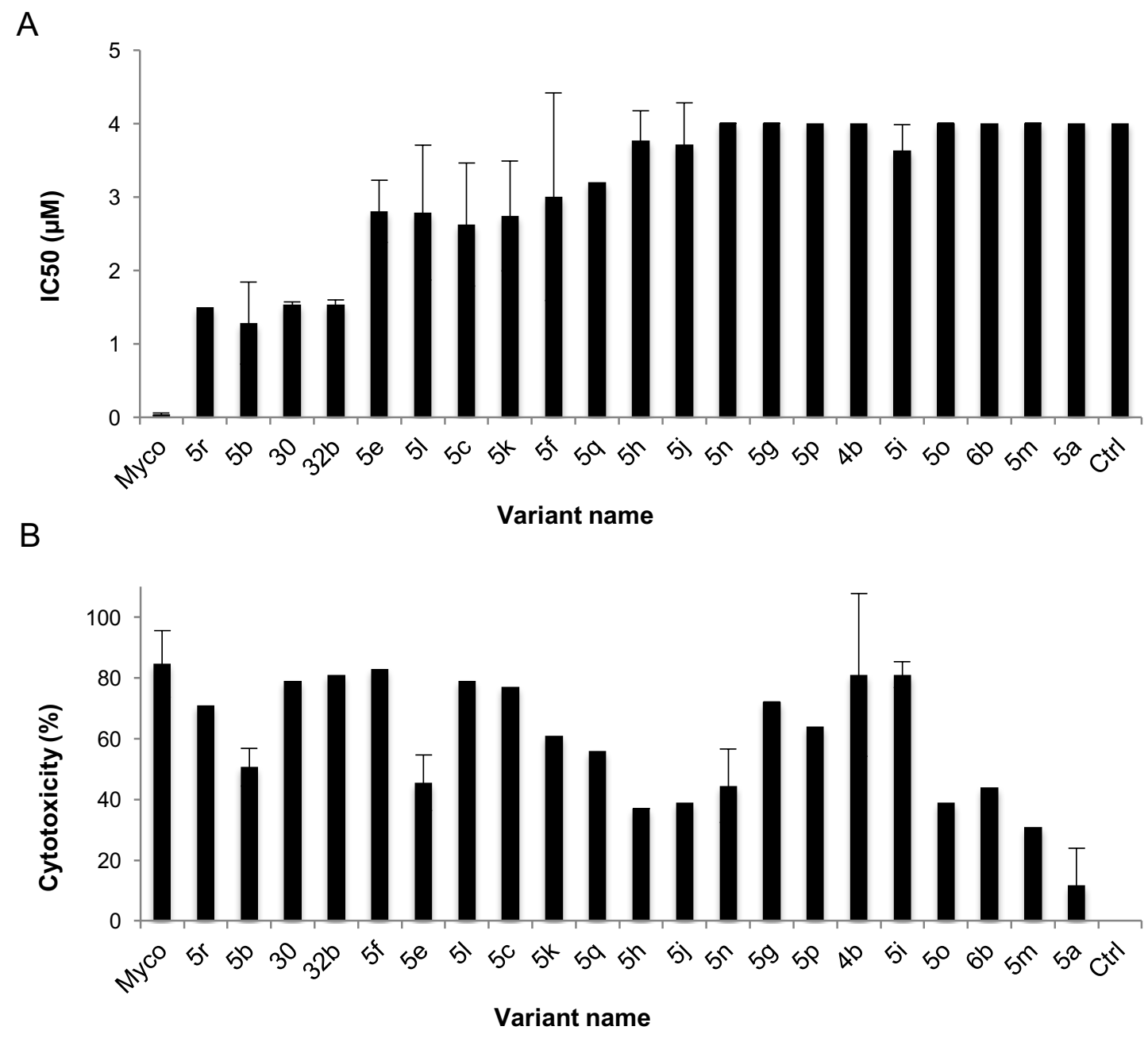

Fig. S1. Compared cytopathic and immunosuppressive effects of mycolactone and variants. The differential capacity of mycolactone and variants to inhibit IL-2 production by activated Jurkat $T$ cells (A) and induce the detachment and death of HeLa cells (B), are shown. Data are means +/- SD measured on $\geq 2$ technical replicates. 

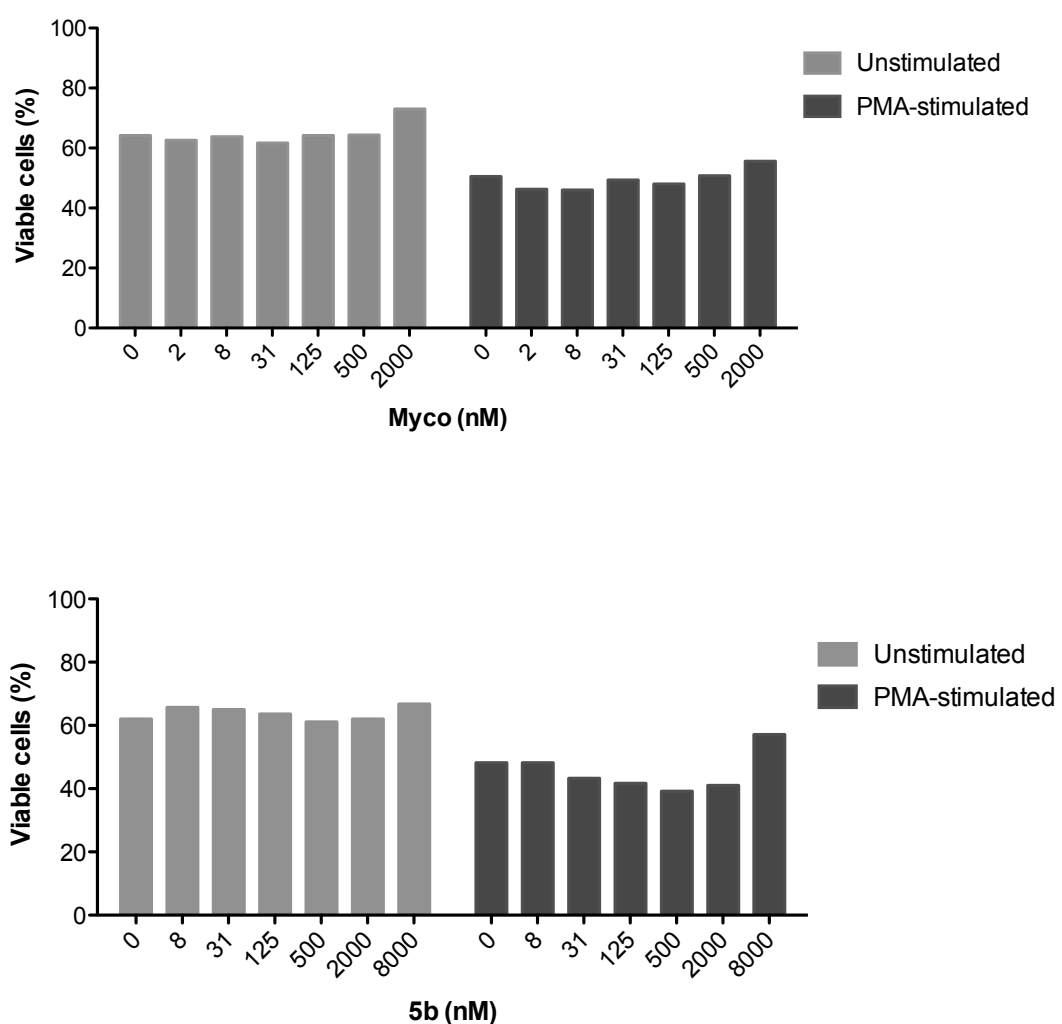

Fig. S2. Viability of human primary PMN exposed to mycolactone or $\mathbf{5 b}$. Peripheral blood-derived PMN were exposed to mycolactone, $\mathbf{5 b}$ or vehicle as control for $20 \mathrm{~h}$, then activated with PMA for $1 \mathrm{~h}$ or not. The percentage of PI negative (viable) cells, as determined by flow cytometry, is shown. Comparable results were obtained in 4 donors. 
A

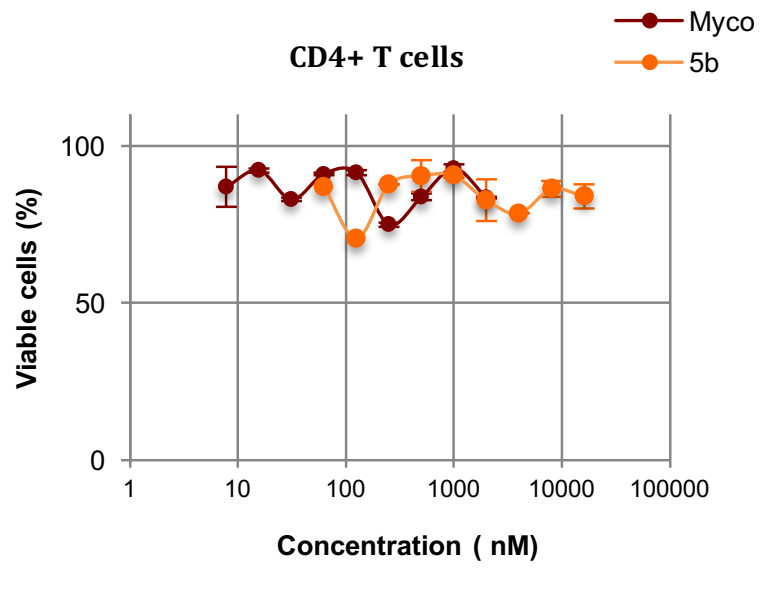

B
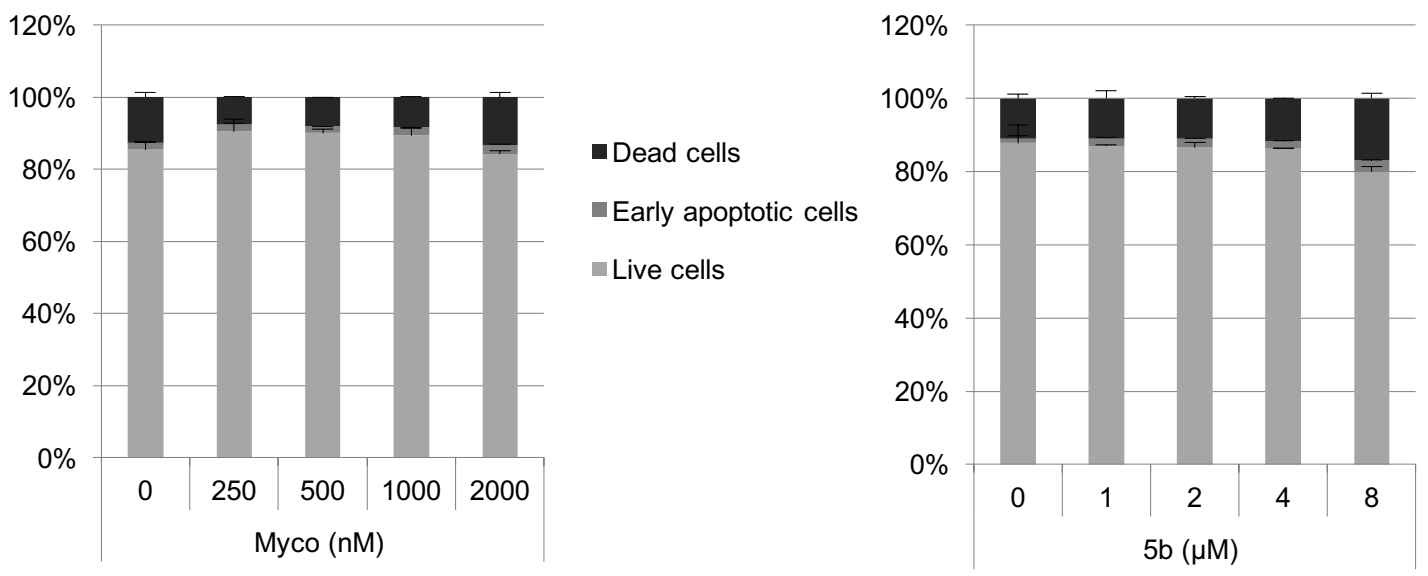

Fig. S3. Viability of human primary $\mathrm{CD}^{+}{ }^{+} \mathrm{T}$ lymphocytes exposed to mycolactone or $\mathbf{5 b}$. Peripheral blood-derived $\mathrm{CD} 4^{+} \mathrm{T}$ lymphocytes were exposed to mycolactone, $\mathbf{5 b}$ or vehicle as control for $48 \mathrm{~h}$. (A) Cell viability, as assessed by MTT reduction. Data are mean percentages +/- SD of duplicates, relative to solvent controls. (B) Induction of cell apoptosis, as evaluated by Annexin V (early apoptosis) and $\mathrm{PI}$ (late apoptosis) staining in flow cytometry. Data are mean percentages from duplicates $+/-S D$ in each category. Comparable results were obtained in 4 donors. 
A

External aspect (periphery)

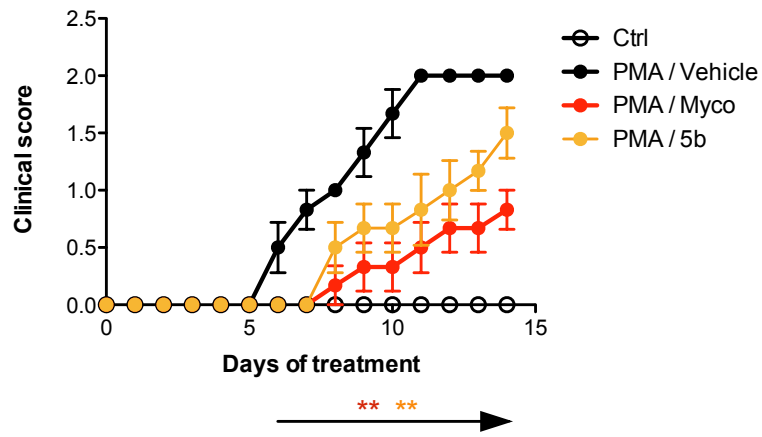

B

Histopathology (dermis)

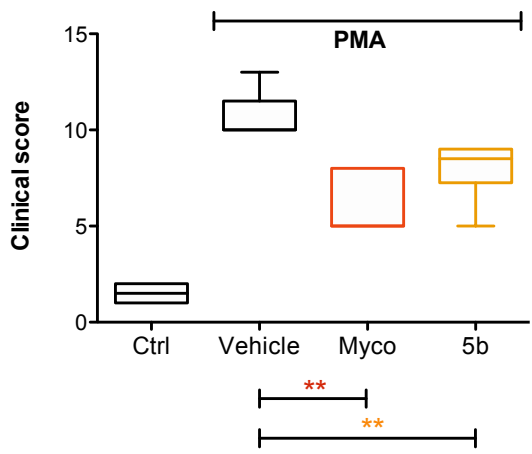

Fig. S4. Protective effect of mycolactone and $\mathbf{5 b}$ against PMA-induced skin inflammation. (A) Clinical scores reflecting the external aspect of mouse skin at the periphery of the site of PMA injection (B) Inflammation scores corresponding to the histopathological analysis of dermis sections. Mice receiving PMA were injected with mycolactone (Myco) or $\mathbf{5 b}$, compared to vehicle controls (Vehicle). Animals not receiving PMA were included as controls (Ctrl). (Mann-Whitney $U$ test on means; $\mathrm{n}=6 ;{ }^{* *} \mathrm{P}<0.01$ vs. PMA/Vehicle). 
A

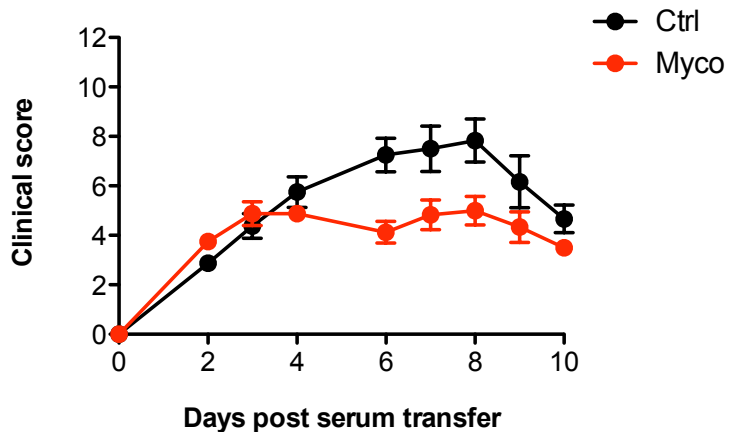

B

Ctrl
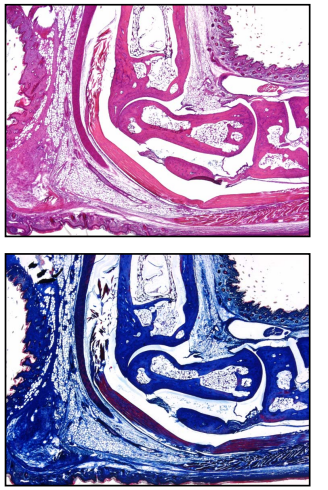

Myco
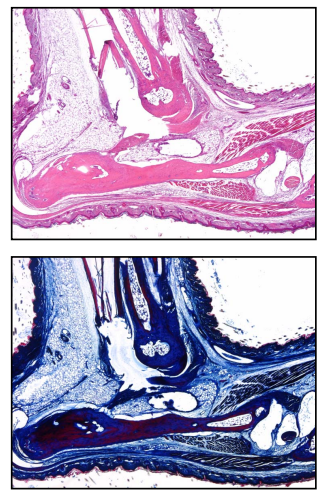

Fig. S5. Protective effect of mycolactone against rheumatoid arthritis. (A) Arthritis score of mice injected with mycolactone (Myco), compared to vehicle controls (Ctrl). (B) H\&E stainings of sections of paraffin-embedded decalcified ankle joints at day 6. Original magnification $\times 20$. C57Bl6 mice were purchased from Jackson Laboratories and KRN TCR transgenic mice on a C57Bl6 background (KRN) provided by $\mathrm{D}$. Mathis and $\mathrm{C}$. Benoist were bred to NOD mice to generate $\mathrm{K} / \mathrm{BxN}$ mice. Passive arthritis was induced by intravenous injection of $34 \mu \mathrm{l}$ serum from $\mathrm{K} / \mathrm{BxN}$ mice. Mice $(\mathrm{n}=8)$ were subcutaneously injected at the base of the tail with Mycolactone $(0.5 \mathrm{mg} / \mathrm{kg})$ or vehicle as control at days -1 and 1 . Arthritis was scored daily for ten days from day 2 post injection of serum, by clinical examination (index of all four paws was added: 0 [unaffected], 1 [swelling of one joint], 2 [swelling of more than one joint], and 3 [severe swelling of the entire paw]). Ankle joints were fixed and decalcified in Formical-4 (Decal Chemical Corp, NY, USA) for two weeks and embedded in paraffin. Six micrometer sections were stained with hematoxylin/eosin (top) or Masson's Trichrome (bottom) for histopathological examination. 
Table S1. Macroscopic and microscopic scoring of PMA-induced skin inflammation

\section{Macroscopic}

The global macroscopic score is the sum of three regional scores, determined as follows:

\begin{tabular}{|l|l|l|l|}
\cline { 2 - 4 } \multicolumn{1}{c|}{} & \multicolumn{2}{c|}{ DEGREE OF SKIN INFLAMMATION } \\
\cline { 2 - 4 } \multicolumn{1}{c|}{} & $\begin{array}{c}\text { Site of PMA } \\
\text { application }\end{array}$ & Periphery & Rest of the dorsum \\
\hline $0=$ None or no more & & & \\
\hline $1=$ Moderate & & & \\
\hline $2=$ Moderately important & & & \\
\hline $3=$ Important & & & \\
\hline $4=$ Very important & & & \\
\hline
\end{tabular}

\section{Microscopic}

The global microscopic score is the sum of the parameters listed below, it defines a level of skin inflammation as follows:

$$
\begin{array}{ll}
\text { From } 0 \text { to } 5 & =\text { Normal skin } \\
\text { From } 6 \text { to } 12 & =\text { Slightly inflammatory skin } \\
\text { From } 13 \text { to } 18 & =\text { Moderately inflammatory skin } \\
\text { From } 19 \text { to } 24 & =\text { Inflammatory skin. } \\
\text { From } 25 \text { to } 30 & =\text { Clearly inflammatory skin } \\
\text { From } 31 \text { to } 36 & =\text { Very inflammatory skin } \\
\text { From } 37 \text { to } 44 & =\text { Hyper-inflammatory skin }
\end{array}
$$

\begin{tabular}{|lll|}
\hline \multicolumn{2}{|l|}{} & EPIDERMIS \\
\hline 0 & $=$ Normal & Stratum corneum \\
\hline 1 & $=$ Area (s) of ulceration & \\
\hline 2 & $=$ Sparse foci of ulceration & \\
\hline 3 & $=$ Abundant foci of ulceration & \\
\hline 4 & $=$ Global ulceration & Granular layer \\
\hline & & \\
\hline 0 & $=$ Normal \\
\hline 1 & $=$ Area (s) of ulceration & \\
\hline 2 & $=$ Sparse foci of ulceration & \\
\hline 3 & $=$ Abundant foci of ulceration & \\
\hline 4 & $=$ Global ulceration \\
\hline & & \\
\hline 0 & $=$ Normal \\
\hline 1 & $=$ Slight hyperkeratosis \\
\hline 2 & $=$ Hyperkeratosis \\
\hline & & \\
\hline 0 & $=$ None & \\
\hline 1 & $=$ Minimal acanthosis \\
\hline 2 & $=$ Moderate acanthosis \\
\hline 3 & $=$ Acanthosis \\
\hline 0 & & \\
\hline 1 & $=$ Normal. \\
\hline 2 & $=$ Destroyed \\
\hline
\end{tabular}




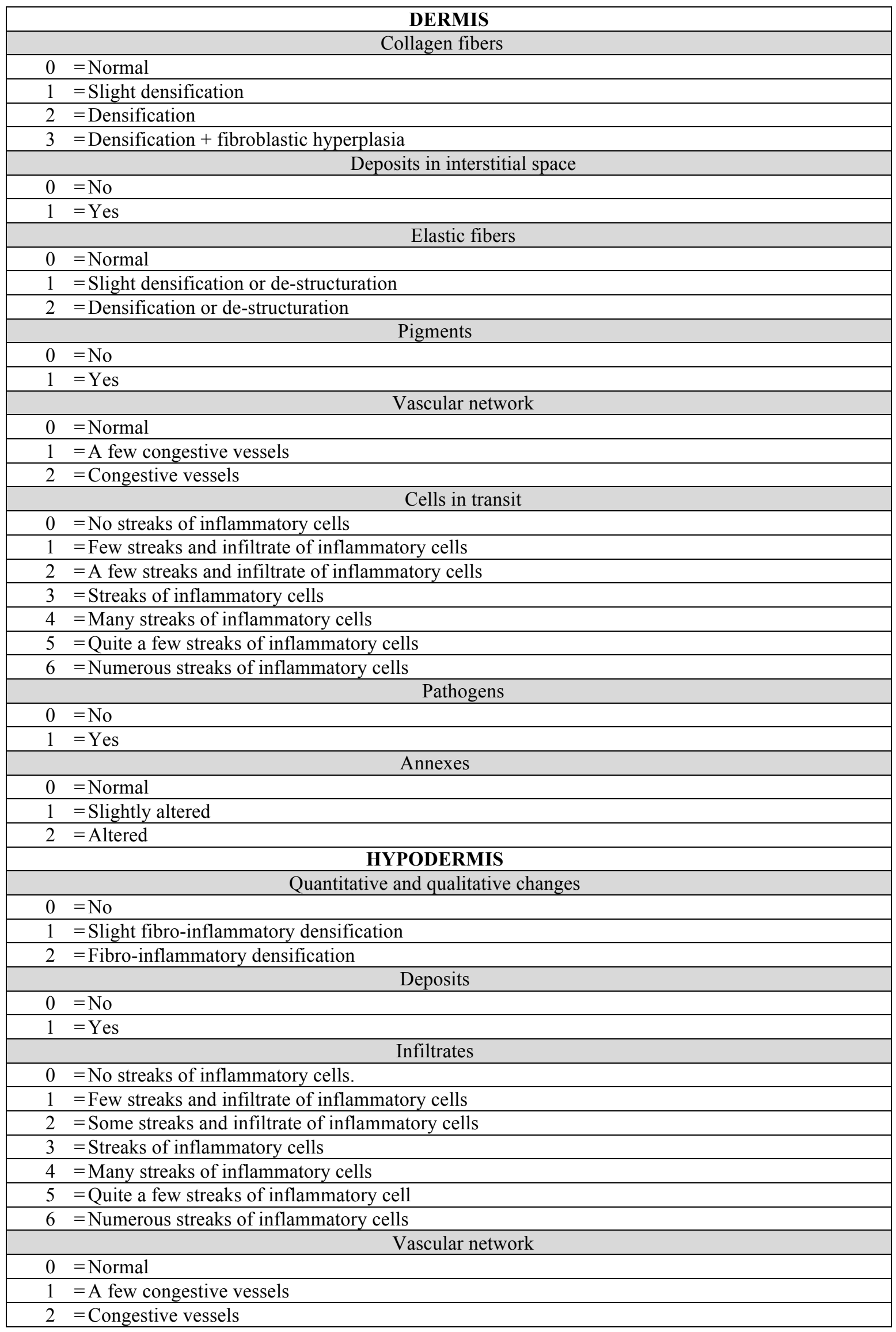

